\title{
The COVID-19 Pandemic Contributed to Disparities in Housing-Cost Burden Among WIC-Participating Households in the Most Populous County in California
}

\author{
Tabashir Z. Nobari ${ }^{1,2}$ (D) Christopher E. Anderson ${ }^{3} \cdot$ Shannon E. Whaley ${ }^{3}$
}

Received: 20 September 2021 / Revised: 26 November 2021 / Accepted: 29 November 2021 / Published online: 7 January 2022

(c) W. Montague Cobb-NMA Health Institute 2021

\begin{abstract}
Affordable housing is necessary for the health and well-being of children and families. The coronavirus disease 2019 (COVID-19) pandemic affected the ability of low-income families to pay for housing. The aim of this study is to evaluate associations between household characteristics of participants of the Special Supplemental Nutrition Program for Women, Infants and Children (WIC), and housing-cost burden during the pandemic. WIC is a federally-funded nutrition assistance program for low-income mothers, infants, and children up to the age of 5. Data were from a 2020 survey of a random sample of WIC households ( $n=5815)$ in Los Angeles County. Ordinal logistic regression determined the odds of being housing-cost burdened by parent respondent's race/ethnicity, household composition, employment, residence, and housing cost. Logistic regression determined if the pandemic contributed to the housing-cost burden. A total of $61 \%$ of households reported housing-cost burden, with two-thirds attributing the burden to the pandemic. Spanish-speaking Hispanic parents and white parents reported a higher prevalence of pandemic-related burden, while Asian, Black, and English-speaking Hispanic parents reported a higher prevalence of burden unrelated to the pandemic. Single-parent households, those experiencing residential instability, and those with high housing costs had higher odds of burden. Spanish-speaking Hispanic parents, white parents, homeowners, and those with high housing costs were more likely to attribute the burden to the pandemic. To ensure that existing inequities are not exacerbated, it is vital that housing assistance be available to low-income households that were disproportionately affected by the pandemic.
\end{abstract}

Keywords Housing-cost burden · COVID-19 pandemic $\cdot$ WIC $\cdot$ Racial/ethnic disparities $\cdot$ Early childhood $\cdot$ Low-income families

\section{Introduction}

Safe, stable, and affordable housing is necessary for the well-being and health of children and families. Even before the pandemic, millions of households were struggling to pay for housing. In 2019, more than 37 million American

Tabashir Z. Nobari

tnobari@fullerton.edu

1 Department of Public Health, California State University, Fullerton, 800 N. State College Blvd., Fullerton, CA 92831, USA

2 Department of Community Health Sciences, UCLA Fielding School of Public Health, Los Angeles, CA, USA

3 Department of Research and Evaluation, PHFE WIC, Irwindale, CA, USA households were housing-cost burdened (spending $>30 \%$ of their income on housing costs), with minority and lowincome households disproportionately affected [1]. Very low-income households may be as much as 10 to 13 times more likely to experience housing-cost burden as their wealthier counterparts [2]. Black and Hispanic households are 1.7 and 1.6 times, respectively, more likely to experience housing-cost burden than non-Hispanic white households [2]. The COVID-19 pandemic and resulting stay-at-home orders implemented in many states and counties, including Los Angeles County, California [3], significantly impacted low-income and minority families. With millions losing their jobs or experiencing pay cuts during the pandemic, many families struggled to make their housing payments [1]. Lowincome households and women were disproportionately represented in the industries that were severely hit by the pandemic, such as service, agriculture, and transportation 
$[4,5]$. Women, especially women of color and single mothers, were more likely to become unemployed during the pandemic compared to men [5, 6]. Women of color and households with children were more likely to fall behind on their housing payments [7, 8]. As of March 2021, a quarter of low-income renter households were still behind on rent, with Black and Hispanic households more likely to still be in arrears compared to white households [1].

While California and many local governments implemented COVID-19 responsive tenant protections, such as eviction moratoriums that impose limits on evictions for failure to pay rent due to financial distress caused by COVID19, low-income households may also experience the most barriers to accessing that assistance, such as limited English, not having an internet connection, and not understanding the renter protection laws [4]. Households that struggle to pay their rent or mortgage can experience a persistently increased risk of food insecurity and having unmet medical needs because the households will cut back on food and medical expenses to pay for their housing [1, 9-15]. Housing-cost burdened adults are more likely to suffer from poor physical and mental health [10,14-16]. Children living in housing-cost burdened households are also more likely to suffer from poor health [17] and poor cognitive outcomes [18] and be exposed to adverse childhood experiences, including food insecurity $[19,20]$.

The aim of this study is to describe housing-cost burden during the COVID-19 pandemic and identify the sociodemographic characteristics associated with housing-cost burden among low-income households with young children. We studied households participating in the Special Supplemental Nutrition Program for Women, Infants and Children (WIC) in Los Angeles County, the most populous county in the nation, where the housing-cost burden is particularly acute [1] and the COVID-19 pandemic was particularly severe [21, 22]. WIC is a federally-funded nutrition assistance program for low-income $[\leq 185 \%$ of the federal poverty level] and at nutritional risk pregnant, breastfeeding, and postpartum women, infants, and children up to their fifth birthday. The reach of WIC is broad, as it provides nutrition education and supplemental food packages to approximately half of all infants in the county [23]. This study also updates our previous work from before the pandemic [19] and provides a current snapshot of the housing-cost burden of WIC households in Los Angeles County.

\section{Methods}

Data came from the 2020 Los Angeles County WIC Survey (lawicdata.org/survey), a triennial survey of a random sample of 6753 WIC-participating families who live in Los Angeles County. Adult respondents are asked questions about the health and behaviors of one child or a pregnant mother, their parenting practices, child care, and their home environment. In 2020, Black and Asian participants were oversampled, as were high-risk communities across LA County that were identified by the funder, First 5 LA (https:// www.first5la.org/best-start-networks/). Computer-assisted phone interviews were conducted in English and Spanish from the last week of July through December 2020. The survey was approved by the Committee for the Protection of Human Subjects for the California Health and Human Services Agency.

\section{Measures}

Our dependent variable was perceived housing-cost burden. The measure was obtained from the answer to the question "How easy or difficult is it for you to pay for housing-very difficult, somewhat difficult, somewhat easy, or very easy?" A response of "somewhat easy" or "very easy" was considered to be "no burden." A response of "somewhat difficult" was considered to be "moderate burden" and response of "very difficult" was considered to be "severe burden." The follow-up question, "Is the difficulty paying for housing related to the COVID pandemic or some other reason?", determined if the burden was at least partially due to the pandemic. For our bivariate analyses, we created a composite housing-cost burden measure that incorporated information from both questions: no burden, moderate burden at least partly due to COVID, moderate burden not due to COVID, severe burden at least partly due to COVID, and severe burden not due to COVID.

Our exposures of interest were race/ethnicity, different dimensions of housing, employment, and household composition. Race/ethnicity was a composite based on the respondent's reported race/ethnicity and preferred language for the interview (English or Spanish). It was categorized as Non-Hispanic (NH) White, NH Black, NH Asian, Englishspeaking Hispanic, and Spanish-speaking Hispanic. For the dimensions of housing, we examined residence type, residential instability, household size, and housing cost. Current residence was determined from the question, "Which of the following best describes where you currently live?" and included: home owned by their parents or relatives; apartment or home that they own; apartment or home that they rent, rented room/space in house or apartment; a shelter, homeless, transitional housing, hotel or motel; garage, or mobile home/RV; or other. A binary residential instability measure determined if they reported moving 2 or more times in the past 3 years. Last month's housing payment was obtained from the question, "How much did your household pay for rent or for a mortgage last month?" and was categorized as nothing (we do not pay rent/mortgage); nothing, we 
skipped last month's payment; $<\$ 500$ a month; $\$ 500$ to $\$ 999$ a month; $\$ 1000$ to $\$ 1499$ a month; $\$ 1500$ to \$1999 a month; and $\geq \$ 2000$ a month.

We examined household measures of composition and employment. A binary single-parent household measure indicated whether the child's other parent did not live in the household. A binary large household measure indicated if there were 5 or more members, including the respondent, currently living in the household. A binary measure, at least 1 parent does not work, was created from the responses "not at all" to the questions, "Are you currently working for pay full-time (at least $35 \mathrm{~h}$ or more), part-time, or not at all?" and "Thinking about the employment situation of your spouse or partner, is he or she currently working for pay full-time (at least $35 \mathrm{~h}$ or more), part-time or not at all?" A binary measure, at least 1 parent works full time, was created from responses of "full-time" to at least one of the employment questions. Essential worker status was determined if they responded "yes" to "Do you work in an industry that is considered an essential service during the COVID pandemic?" or to "Does your spouse work in an industry that is considered an essential service during the COVID pandemic?" Since these measures determine employment stability and type of employment, all households, including single-parent households, were included in these three employment measures. Pregnancy status indicated whether the respondent reported being pregnant at the time of the interview.

Because minority and low-income households are at greater risk of experiencing housing-cost burden [1,2], the regression analyses adjusted for household income during the past month $[<\$ 1200, \$ 1200$ to $\$ 1800, \$ 1800$ to $\$ 2400,>\$ 2400]$, and respondent's educational attainment [less than high school, high school, some college, college or more]. For the models where our exposures of interest were the different dimensions of housing, employment, and household composition, we also adjusted for race/ethnicity since households of different racial/ethnic backgrounds experience different rates of housing-cost burden [1,2].

\section{Analyses}

Differences in housing-cost burden by each independent variable were assessed with Rao-Scott chi-square tests. Associations between housing-cost burden (no burden, moderate burden, and severe burden) and each of the exposures of interest were assessed with ordinal logistic regression models, adjusting for parent's race/ethnicity, educational attainment, and monthly household income. Among those who experienced housing-cost burden, logistic regression models were used to test associations between each exposure of interest and whether the housing-cost burden was in part due to the COVID-19 pandemic, adjusting for parent's race/ ethnicity, educational attainment, and household income.
Due to small sample sizes for multiple response categories for race/ethnicity and residence type variables, the largest categories (English-speaking Hispanic, and apartment or home they rent) were selected as the referent category to provide estimated measures of association of greater precision. Analyses were weighted to address the oversampling. Our final analytic sample included 5815 subjects. Analyses were conducted using SAS 9.4 (SAS Institute, Cary, NC, USA).

\section{Results}

The majority of households were Hispanic, had a monthly household income less than or equal to $\$ 1800$, and had no more than a high school degree (Table 1). Approximately one third of households only had one parent. At least one parent did not work in one third of all households. However, in nearly half of households, there was no parent who worked full time. Almost half of the households had at least one parent who reported being an essential worker. The majority of households (73\%) lived in an apartment or home that they rented. More than half of households spent between $\$ 1000$ and $\$ 1999$ on their rent. Only 2\% of households reported being unable to make their last month's housing payment. A total of $61 \%$ of households experienced housing-cost burden (moderate and severe), with approximately two-thirds of them reporting that the burden was at least partly due to the COVID-19 pandemic (Table 1).

The prevalence of housing-cost burden by each of the sociodemographic measures and exposures of interest are in Table 1. Spanish-speaking Hispanic households experienced the highest prevalence of total housing-cost burden, followed by NH White households (Table 1). English-speaking Hispanic households experienced the lowest prevalence. Spanish-speaking Hispanics and NH whites reported more COVID-19-related housing-cost burden than other groups (Fig. 1). NH Asian, NH Black, and English-speaking Hispanic households reported experiencing a higher prevalence of housing-cost burden that was not attributable to the COVID-19 pandemic (Fig. 1).

A dose-response relationship existed with household income; households with lower monthly income experienced a higher prevalence of total housing-cost burden (Table 1). This appears to be because of the higher prevalence of pandemic-related burden that lower-income households experienced (Fig. 2). Households where the respondent had less than a high-school education experienced the highest prevalence of housing-cost burden (Table 1). More than $60 \%$ of households that had a pregnant mother, had a single parent, or consisted of five or more people reported being housingcost burdened (Table 1). Households that did not have a parent who worked full-time experienced a high prevalence 
Table 1 Sociodemographic and household characteristics of our sample, 2020 Los Angeles County WIC Survey $(n=5815)$

\begin{tabular}{|c|c|c|c|}
\hline & Unweighted \% (no.) & $\begin{array}{l}\text { Weighted sample } \\
\%(95 \% \text { CI })\end{array}$ & $\begin{array}{l}\text { Prevalence of housing- } \\
\text { cost burden } \%(95 \% \mathrm{CI})\end{array}$ \\
\hline \multicolumn{4}{|l|}{ Parent's race/ethnicity } \\
\hline Hispanic-English speaking & $38.0(2207)$ & $53.4(52.1,54.8)$ & $53.7(51.6,55.8)$ \\
\hline Hispanic-Spanish speaking & $35.9(2085)$ & $30.0(28.8,31.2)$ & $74.0(72.1,75.9)$ \\
\hline NH Black & $10.3(600)$ & $9.0(8.3,9.7)$ & $58.4(54.4,62.5)$ \\
\hline NH White & $4.2(244)$ & $4.8(4.2,5.5)$ & $67.3(60.9,73.8)$ \\
\hline NH Asian & $11.7(679)$ & $2.7(2.5,2.9)$ & $65.1(61.5,68.8)$ \\
\hline \multicolumn{4}{|l|}{ Last month's household income } \\
\hline$<\$ 1200$ & $31.2(1812)$ & $32.3(30.9,33.6)$ & $69.2(66.9,71.6)$ \\
\hline$\$ 1200-\$ 1800$ & $32.0(1863)$ & $31.5(30.2,32.8)$ & $64.4(62.0,66.8)$ \\
\hline$\$ 1800-\$ 2400$ & $23.7(1379)$ & $23.6(22.4,24.7)$ & $55.0(52.1,57.9)$ \\
\hline$>\$ 2400$ & $13.1(761)$ & $12.7(11.7,13.6)$ & $44.1(40.1,48.1)$ \\
\hline \multicolumn{4}{|l|}{ Parent's educational attainment } \\
\hline Less than high school & $26.5(1540)$ & $24.4(23.3,25.5)$ & $70.9(68.5,73.3)$ \\
\hline High school & $29.5(1718)$ & $30.7(29.4,32.0)$ & $59.1(56.6,61.7)$ \\
\hline Some college & $30.1(1751)$ & $33.3(31.9,34.6)$ & $55.9(53.4,58.4)$ \\
\hline College or more & $13.9(806)$ & $11.7(10.8,12.6)$ & $61.1(57.1,65.1)$ \\
\hline Pregnant & $5.9(343)$ & $6.3(5.6,7.0)$ & $61.0(59.5,62.4)$ \\
\hline \multicolumn{4}{|l|}{ Household composition } \\
\hline Single-parent household ${ }^{\mathrm{a}}$ & $33.1(1927)$ & $35.3(34.0,36.7)$ & $62.9(60.6,65.2)$ \\
\hline Large household ${ }^{\mathrm{b}}$ & 47.8 (2777) & $47.5(46.1,48.9)$ & $61.5(59.5,63.5)$ \\
\hline \multicolumn{4}{|l|}{ Household employment } \\
\hline At least 1 parent does not work & $32.0(1863)$ & $33.4(32.1,34.8)$ & $63.1(61.4,64.7)$ \\
\hline No parent works full-time & $49.2(2860)$ & $48.8(47.4,50.2)$ & $68.8(67.0,70.7)$ \\
\hline At least 1 parent is an essential worker & $46.2(2685)$ & $47.4(46.0,48.8)$ & $57.2(55.2,59.3)$ \\
\hline \multicolumn{4}{|l|}{ Housing-cost burden } \\
\hline No housing-cost burden & $36.9(2144)$ & $38.8(37.5,40.2)$ & - \\
\hline Moderate burden at least partly due to the pandemic & $31.1(1806)$ & $29.7(28.5,31.0)$ & - \\
\hline Moderate burden not due to the pandemic & $16.3(1806)$ & $16.0(15.0,17.0)$ & - \\
\hline Severe burden at least partly due to the pandemic & $10.7(621)$ & $10.3(9.5,11.2)$ & - \\
\hline Severe burden not due to the pandemic & $5.1(297)$ & $5.1(4.5,5.8)$ & - \\
\hline \multicolumn{4}{|l|}{ Residence } \\
\hline Apartment or home they rent & $73.8(4294)$ & $73.1(71.8,74.3)$ & $63.1(64.7,61.5)$ \\
\hline Apartment or home they own & $6.6(383)$ & $5.8(5.2,6.4)$ & $48.0(42.3,53.7)$ \\
\hline Home owned by parents or relatives & $17.0(987)$ & $18.8(17.6,19.9)$ & $56.7(53.3,60.0)$ \\
\hline Rents a room/space in house or apartment & $1.3(77)$ & $1.2(0.9,1.5)$ & $67.9(45.8,89.9)$ \\
\hline Shelter, homeless, transitional housing, hotel or motel & $0.3(19)$ & $0.3(0.2,0.5)$ & $67.0(55.5,78.5)$ \\
\hline Garage or mobile home/RV & $0.6(36)$ & $0.5(0.3,0.7)$ & $77.8(62.0,93.6)$ \\
\hline Other & $0.3(19)$ & $0.3(0.1,0.4)$ & $61.5(38.0,85.1)$ \\
\hline \multicolumn{4}{|l|}{ Last month's housing payment } \\
\hline Nothing & $3.6(210)$ & $3.4(2.9,4.0)$ & $48.8(41.2,56.4)$ \\
\hline$<\$ 500$ & $5.6(324)$ & $5.8(5.1,6.4)$ & $54.8(49.0,60.7)$ \\
\hline$\$ 500-\$ 999$ & $24.6(1432)$ & $25.6(24.3,26.8)$ & $56.2(53.4,59.0)$ \\
\hline$\$ 1000-\$ 1499$ & $35.0(2036)$ & $35.0(33.7,36.3)$ & $63.7(61.4,66.0)$ \\
\hline$\$ 1500-\$ 1999$ & $20.0(1164)$ & $19.6(18.5,20.8)$ & $65.0(62.0,68.1)$ \\
\hline$\geq \$ 2000$ & $9.3(539)$ & $8.9(8.1,9.7)$ & $60.7(56.0,65.4)$ \\
\hline Could not make last month's payment & $1.9(110)$ & $1.7(1.4,2.1)$ & $86.8(78.8,94.8)$ \\
\hline Residential instability ${ }^{\mathrm{c}}$ & $7.2(416)$ & $7.0(6.3,7.7)$ & $72.5(67.7,77.2)$ \\
\hline
\end{tabular}

$N H$, non-Hispanic

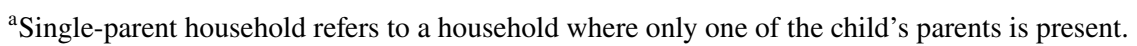

${ }^{\mathrm{b}}$ Large household includes 5 or more persons.

${ }^{\mathrm{c}}$ Residential instability refers to 2 or more moves in the last 3 years 


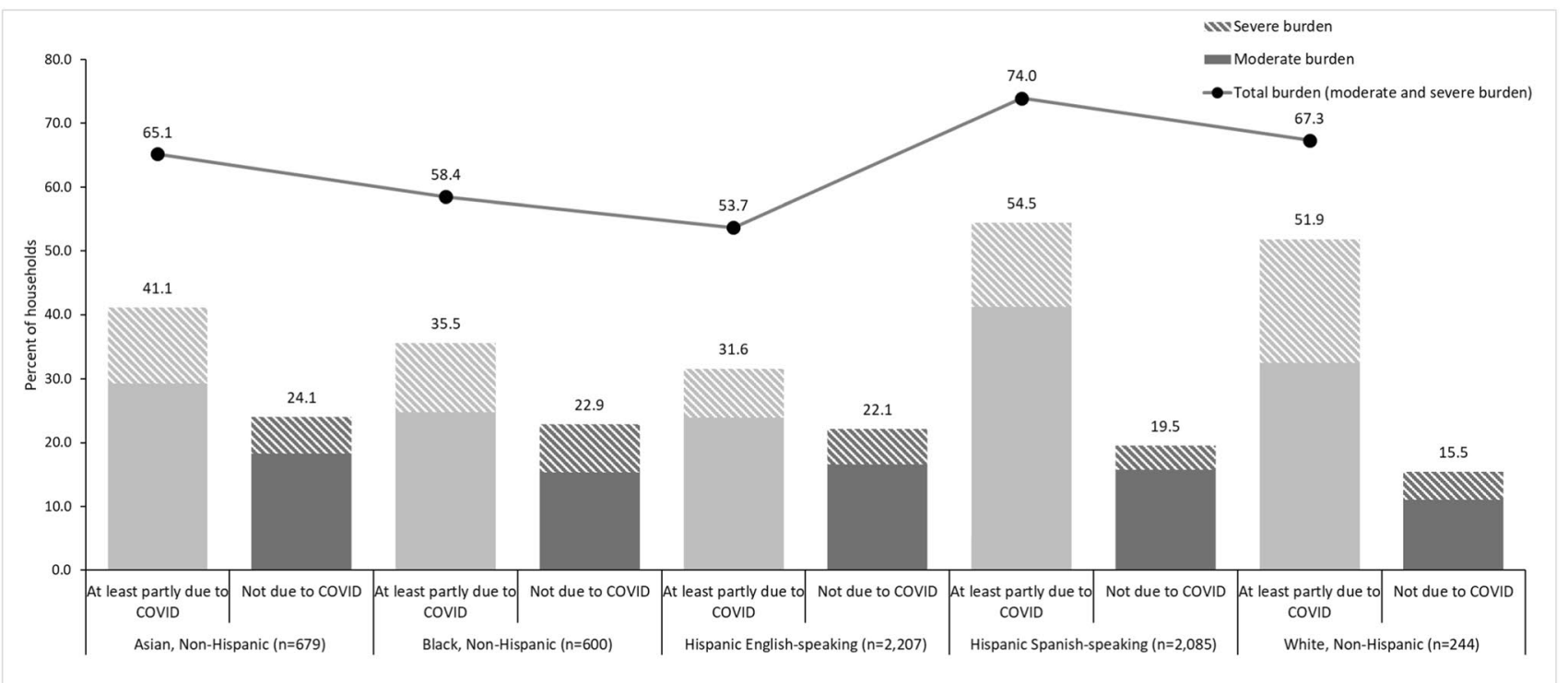

Fig. 1 Prevalence of housing-cost burden by parent respondent's race/ethnicity, 2020 Los Angeles County WIC Survey ( $n=5815$ ). Note: RaoScott chi-square test of differences of housing-cost burden by race/ethnicity, $p$-value $=<0.0001$

of burden while households with at least one parent who was an essential worker experienced a lower prevalence of housing-cost burden (Table 1).

Differences in housing-cost burden existed by place of residence (Table 1). Households that owned their residence or lived with parents or relatives experienced a lower prevalence of housing-cost burden, while those living in a garage or mobile home/RV experienced a high prevalence of burden. Households with higher monthly housing costs experienced a higher prevalence of housing-cost burden (Table 2). Those who were not able to make last month's housing payment experienced the highest prevalence of burden. Housing-cost burden was also reported among those who do not pay rent or a mortgage. Nearly three quarters of residentially unstable households reported experiencing housing-cost burden.

Even after controlling for educational attainment and household income, those who were Spanish-speaking

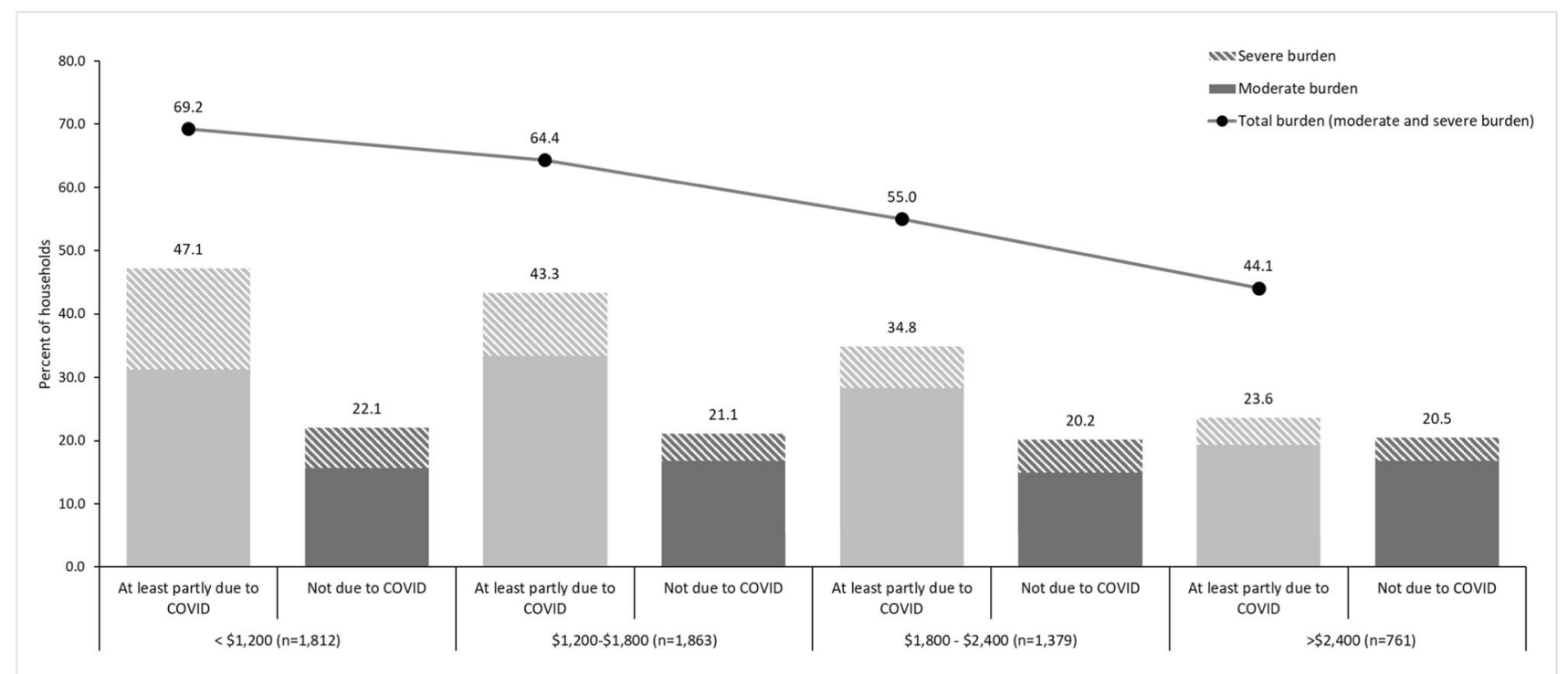

Fig. 2 Prevalence of housing-cost burden by monthly household income, 2020 Los Angeles County WIC Survey $(n=5815)$. Note: Rao-Scott chi-square test of differences of housing-cost burden by monthly household income, $p$-value $=<0.0001$ 
Table 2 Adjusted odds ratios for the association of each of the household measures with increasing severity of housing-cost burden (model 1) and with housing cost-burden partly due to the COVID pandemic (model 2), 2020 Los Angeles County WIC Survey $(n=5815)$

\begin{tabular}{|c|c|c|}
\hline & $\begin{array}{l}\text { Model } 1 \\
\text { aOR }(95 \% \text { CI })\end{array}$ & $\begin{array}{l}\text { Model } 2 \\
\text { aOR }(95 \% \mathrm{CI})\end{array}$ \\
\hline \multicolumn{3}{|l|}{ Parent's race/ethnicity ${ }^{\mathrm{a}}$ (Ref = English-speaking Hispanic) } \\
\hline Spanish-speaking Hispanic & $1.87(1.64,2.13)^{\mathrm{b}}$ & $2.12(1.75,2.56)$ \\
\hline White & $1.86(1.48,2.35)$ & $2.28(1.48,3.52)$ \\
\hline Black & $1.27(1.06,1.51)$ & $1.05(0.81,1.35)$ \\
\hline Asian & $1.61(1.19,2.20)$ & $1.20(0.93,1.54)$ \\
\hline Pregnant $(\operatorname{Ref}=$ not pregnant $)$ & $1.12(0.90,1.40)$ & $0.86(0.64,1.18)$ \\
\hline \multicolumn{3}{|l|}{ Household composition } \\
\hline Single parent $(\operatorname{Ref}=2$ parents $)$ & $1.21(1.07,1.37)$ & $0.59(0.50,0.70)$ \\
\hline Large household ( $\operatorname{Ref}=<5$ members) & $1.02(0.91,1.14)$ & $1.09(0.93,1.27)$ \\
\hline \multicolumn{3}{|l|}{ Household employment } \\
\hline$\geq 1$ full-time employed parent $(\operatorname{Ref}=$ no full-time employed parent) & $0.60(0.54,0.68)$ & $0.52(0.44,0.62)$ \\
\hline$\geq 1$ parent without a job $(\operatorname{Ref}=$ no parent without a job $)$ & $1.05(0.93,1.18)$ & $1.55(1.32,1.83)$ \\
\hline $\begin{array}{l}\geq 1 \text { parent is essential worker }(\operatorname{Ref}=\text { at least one working parent who is not } \\
\text { an essential worker) }(n=4613)\end{array}$ & $1.12(0.97,1.28)$ & $0.87(0.71,1.06)$ \\
\hline Residential instability ( $\operatorname{Ref}=<2$ moves in 3 years) & $1.62(1.32,1.99)$ & $0.95(0.72,1.25)$ \\
\hline \multicolumn{3}{|l|}{ Last month's housing payment ( $\operatorname{Ref}=$ does not pay anything) } \\
\hline $\begin{array}{l}\text { Could not pay last month } \\
<\$ 500 \\
\$ 500 \text { to } \$ 999 \\
\$ 1000 \text { to } \$ 1499 \\
\$ 1500 \text { to } \$ 1999 \\
\geq \$ 2000\end{array}$ & $\begin{array}{l}\mathbf{6 . 1 3}(\mathbf{3 . 5 7}, \mathbf{1 0 . 5 3}) \\
1.22(0.80,1.85) \\
1.13(0.79,1.61) \\
\mathbf{1 . 5 7}(\mathbf{1 . 1 1}, \mathbf{2 . 2 3}) \\
\mathbf{1 . 8 5}(\mathbf{1 . 2 9}, \mathbf{2 . 6 5}) \\
\mathbf{1 . 7 3}(\mathbf{1 . 1 8}, \mathbf{2 . 5 5})\end{array}$ & $\begin{array}{l}\mathbf{3 . 8 6}(\mathbf{1 . 8 3}, \mathbf{8 . 1 2}) \\
1.20(0.70,2.07) \\
1.44(0.91,2.29) \\
\mathbf{1 . 7 4}(\mathbf{1 . 1 0 , 2 . 7 4 )} \\
\mathbf{1 . 8 7}(\mathbf{1 . 1 7}, \mathbf{3 . 0 0}) \\
\mathbf{1 . 8 9}(\mathbf{1 . 1 3}, \mathbf{3 . 1 5})\end{array}$ \\
\hline \multicolumn{3}{|l|}{ Residence $(\operatorname{Ref}=$ apartment or home they rent) } \\
\hline Home owned by parents/relatives & $1.05(0.89,1.22)$ & $0.62(0.50,0.76)$ \\
\hline Apartment/home they own & $0.73(0.57,0.93)$ & $2.31(1.54,3.47)$ \\
\hline Renting a room or space & $1.17(0.44,3.11)$ & $0.90(0.28,2.90)$ \\
\hline Mobile home, RV, or garage & $0.80(0.52,1.24)$ & $1.51(0.75,3.03)$ \\
\hline Shelter, transitional housing, hotel, motel, and homeless & $1.92(0.99,3.72)$ & $0.84(0.36,1.97)$ \\
\hline Other & $0.69(0.29,1.67)$ & $0.51(0.16,1.62)$ \\
\hline
\end{tabular}

$a O R$, adjusted odds ratio, $C I$, confidence interval

Ordinal logistic regression (model 1) was used to model the change in odds of 1-category more severe housing-cost burden. Logistic regression (model 2) was used to model the change in odds of COVID-19 contributing to housing-cost burden among households experiencing housing-cost burden. Except for the model for race/ethnicity, all the models are adjusted for respondent's race/ethnicity, educational attainment and monthly household income

${ }^{a}$ Model is adjusted for respondent's educational attainment and monthly household income.

${ }^{\mathrm{b}}$ Values in bold are statistically significant.

Hispanic, NH Black, NH Asian, and NH White had greater odds of experiencing housing-cost burden compared to English-speaking Hispanic households (model 1, Table 2). Spanish-speaking Hispanic households [adjusted odds ratio (aOR) and 95\% confidence intervals (CI): 2.12 (1.75, 2.56)] and NH White households [aOR (95\% CI): 2.28 $(1.48,3.52)]$ were more than twice as likely to attribute the housing-cost burden to the pandemic than English-speaking Hispanic households (model 2, Table 2). After controlling for parent's race/ethnicity, educational attainment and household income, the following groups had statistically significantly greater odds of experiencing housing-cost burden than their counterparts: households with a single parent; experienced residential instability; paid more than $\$ 1000$ in housing costs or could not make last month's housing payment (model 1, Table 2). Households with at least one full-time employed parent [aOR (95\% CI): 0.60 $(0.54,0.68)]$, and those that owned their own homes [aOR (95\% CI): $0.73(0.57,0.93)]$ had significantly lower odds of experiencing housing-cost burden (model 1, Table 2). The pandemic was more likely to be part of the cause of the burden for households with at least one parent who was not working, who were paying $\geq \$ 1000$ in housing costs or not able to pay for their housing and those that owned their 
home (model 2, Table 2). There were significantly lower odds of the pandemic being the cause of the burden for households where there was only one parent [aOR $(95 \% \mathrm{CI})$ : $0.59(0.50,0.70)]$, at least one full-time employed parent [aOR (95\% CI): $0.52(0.44,0.62)$ ], and if they were living in a home owned by parents or relatives [aOR $(95 \% \mathrm{CI}): 0.62$ $(0.50,0.76)]$ (model 2, Table 2).

\section{Discussion}

Our study of WIC-participating households in one of the most expensive housing markets in the nation found that more than $60 \%$ experienced housing-cost burden and twothirds of these households reported the burden to be attributable, at least in part, to the pandemic. Compared to English-speaking Hispanics, all racial/ethnic groups reported a higher prevalence of housing-cost burden. However, only Spanish-speaking Hispanic households and NH White households were significantly more likely than Englishspeaking Hispanic households to experience the burden because of the COVID-19 pandemic.

While other researchers have found that low-income Hispanic households were more likely than their $\mathrm{NH}$ white counterparts to be unable to pay for housing during the pandemic $[1,2]$, we found that differences exist based on the primary language spoken. Spanish-speaking Hispanic households experienced the highest rate of housing-cost burden while English-speaking Hispanic households experienced the lowest rate. Language is an indicator of acculturation [24], and when we explored the issue, we found that Spanish-speaking Hispanic households were more vulnerable to a crisis than their English-speaking counterparts. They were significantly less likely than their English-speaking counterparts to have graduated high school (42\% vs. $89 \%$ ), to be an essential worker (51\% vs. $75 \%$ ), to live in a home owned by their parents/relatives (5\% vs. $26 \%$ ) and to be able to turn to someone if they needed practical help (63\% vs. 86\%). Finally, Spanish-speaking Hispanic households may have been less likely to receive the three federal economic impact payments (the stimulus checks). Undocumented immigrants, those who file using an Individual Taxpayer Identification Number (ITIN) instead of a social security number, and mixed immigration status families with an ITIN holder were initially ineligible for the stimulus checks [25]. It was only in December 2020, the end of the data collection for the Los Angeles County WIC Survey, that mixed immigration status families with an ITIN holder could qualify [25]. Finally, in February 2021, California voted to provide a stimulus payment of $\$ 600$ to eligible undocumented taxpayers who were not able to receive the federal stimulus payments [26].

Contrary to other studies, we did not find that Black households were more likely than non-Hispanic white households to experience pandemic-related housing-cost burden. Black WIC-participating households may be more likely than white households to "stretch their finances" [27]. It might also be that they had a more stable employment status. We found that $60 \%$ of Black WIC-participating households reported having a parent without a job compared to $71 \%$ of non-Hispanic white households; $80 \%$ had at least one essential worker compared to $62 \%$ of non-Hispanic whites. Due to the long-standing systemic racism in the housing and labor markets [28], Black households may also have support networks in place to help them weather the crisis. We found that $85 \%$ reported that they had someone they could turn to if they needed practical help versus $63 \%$ of Spanish-speaking Hispanic households. A study by Threet and colleagues [29] found that half of the households with no confidence in their ability to pay their rent were likely to rely on friends and family to pay bills.

Similar to prior publications, housing-cost burden was more prevalent among households that were low-income or headed by a single parent, or who had a parent who was unemployed or with low educational attainment $[1,30,31]$. Among this low-income sample, housing-cost burden was more prevalent among those with higher housing costs. However, housing-cost burden was also reported among those who did not pay rent or a mortgage. While they might not be responsible to pay for housing every month, these families might have an arrangement to contribute to household costs, such as rent or utilities.

Housing-cost burden varied by type of residence. Living in a home owned by parents or relatives decreased the likelihood that households would experience housing-cost burden due to the pandemic. Living with relatives can provide protection as they may not have to pay the full amount of housing or they may be able to rely on relatives to cover the cost of housing. Similar to other research, housing-cost burden was less prevalent among homeowners [1]. The wealth and equity that homeownership can provide $[32,33]$ may protect against crises. However, among those who did experience burden, the burden was more likely to be attributable to the pandemic. Data from the Census Household Pulse Survey show that low-income families were more likely to be behind on their mortgages in early 2021 [1]. The CARES Act that was signed in March 2020 included moratoriums on foreclosures for certain types of home loans and provided COVID-19-related 18-month forbearance plans to those with federally backed mortgage loans. The federal foreclosure moratorium ended July 31, 2021 [34], and it may be difficult for low-income households to pay the missed payments [1]. Families who are not caught up on their housing payments when eviction moratorium and rental assistance programs end, may be more likely to be food insecure, and to be unable to pay needed expenses like child care and medical bills $[1,11,20]$. 
While we did not ask about rental assistance, relatively few households in California had obtained rent relief. As of June 2021 , only $8 \%$ of those who had applied had received aid [35], partly due to a shortage of staff to process the applications [36]. With billions in aid available for California households, the lengthy application process has since been streamlined and is now available in six different languages [37]. However, more needs to be done to ensure that households are aware of the program [37] and that barriers to access aid are lifted. The circumstances of the household can make it more difficult to compile all the paperwork needed [38] to apply for assistance, such as single parents caring for young children; household members with limited education or precarious employment situations; households without internet, an email address or the ability to upload documents; and households with an informal lease $[4,37,39]$. Having the application in only six languages, sometimes with incorrect translation, makes it difficult for non-English speakers to complete the application process [37, 39]. Households who still worry about being deemed a public charge may also be less likely to apply for assistance. While city, county, and federal support helped many renters stay in their homes, waitlists for rental assistance programs in Los Angeles County and City are currently closed. The Los Angeles County Temporary Eviction Moratorium prevents tenants from being evicted due to COVID-19 related financial distress as well as other COVID-19 related reasons. While the eviction moratorium was extended to September 30, 2021 [40], landlords can still evict tenants for reasons unrelated to the pandemic. California recently proposed to pay $100 \%$ of the unpaid rent of low-income families [35]. It is possible that this will have a significant impact on addressing housing-cost burden and preventing evictions. The scope of the program is unprecedented [35] and its effectiveness will need to be studied.

This study's strengths include a large, well-characterized sample randomly drawn from a defined sampling frame. Analyses incorporated statistical weights to ensure respondents were representative of all English- and Spanish-speaking WIC-participating families in Los Angeles County in April 2020. The sample of low-income families in one of the most expensive housing markets in the nation ensured a high prevalence of housing-cost burden, allowing sufficient statistical power to evaluate multiple categories of severity and whether COVID-19 contributed to the housing-cost burden. Furthermore, many studies and reports only examine differences in housing-cost burden by race/ethnicity and household income. We studied housing-cost burden by different dimensions of housing, employment, household composition, and language preference.

Limitations of the study include the observational study design precluding causal inference. The measure used for housing-cost burden is a perceived measure and not an objective measure based on the share of their gross income spent on housing. However, perceived measures are frequently used in research $[14,15,41]$. They may better capture difficulty paying for housing since objective measures do not account for the number of household members who rely on the income [14, 42]. The cross-sectional study design does not allow for the assessment of the directionality of some associations. For instance, we are not able to ascertain if families moved in with parents or relatives as a consequence of the pandemic or if they lived with them before the pandemic began. Additionally, our findings may not be generalizable to other counties in the US with different housing markets and demographics or to families who are not low-income with young children.

Our findings describe the sociodemographic characteristics of families who experienced housing-cost burden during the pandemic and highlight the extent that the pandemic has affected the ability of low-income families with young children to pay for their housing. To ensure the pandemic does not exacerbate child health inequities, it is important to identify households who are struggling to pay for housing, ensure the application process for rental assistance is easy, and provide enrollment assistance to those who need it. While state and federal policy solutions have focused on addressing the housing-cost burden caused by the pandemic, it is also critical to not lose sight of the households who experience burden unrelated to the pandemic.

Acknowledgements We gratefully acknowledge Catherine Martinez for her contributions to this work and to Hannah Peterson, Monica Avila, and Dordaneh Ashouriha for their research assistance. We also thank First 5 LA for funding the 2020 Los Angeles County WIC Survey.

Author Contribution TZN developed the research question; TZN and SEW conceptualized the study design; TZN, CEA, and SEW conceptualized the analysis approach; TZN conducted the data analysis; TZN drafted the manuscript and all authors reviewed and approved the final manuscript version.

Funding First 5 LA funded the 2020 Los Angeles County WIC Survey.

Data Availability The data are not publicly available. However, data inquiries can be submitted to lawicdata.org/requests.

Code Availability Not applicable.

\section{Declarations}

Ethics Approval The 2020 Los Angeles County WIC Survey was approved by the Committee for the Protection of Human Subjects for the California Health and Human Services Agency. The California State University, Fullerton Institutional Review Board (CSUF IRB) approved this study.

Consent to Participate Informed consent to participate in the 2020 Los Angeles County WIC Survey was obtained from all respondents. 
Consent for Publication Not applicable.

Conflicts of Interest The authors declare no competing interests.

\section{References}

1. Joint Center for Housing Studies of Harvard University. The state of the nation's housing. Cambridge, MA: Harvard University; 2021. Available from: https://www.jchs.harvard.edu/sites/ default/files/reports/files/Harvard_JCHS_State_Nations_Housi ng_2021.pdf

2. Joint Center for Housing Studies of Harvard University. State of the nation's housing appendix and web tables: Tables A2 and WI. Cambridge, MA: Harvard University; 2020. Available from: https://www.jchs.harvard.edu/sites/default/files/inter active-item/files/Harvard_JCHS_SON_2020_Appendix_Table_ 120720.xlsx.

3. County of Los Angeles Department of Public Health Order of the Health Officer. Safer at home order for control of COVID19: temporary prohibition of events and gatherings of 10 persons or more closure of non-essential businesses and areas. March 19, 2020. Available from: http://file.lacounty.gov/SDSIn ter/lac/1070029_COVID-19_SaferAtHome_HealthOfficerOr der_20200319_Signed.pdf

4. Ong P, Pech C, Ong E, Gonzalez S, Ong J. Economic impacts of the COVID-19 crisis in Los Angeles: identifying renter-vulnerable neighborhoods. Los Angeles, CA: UCLA Center for Neighborhood Knowledge; 2020. Available from: https://www.ander son.ucla.edu/documents/areas/ctr/ziman/UCLA-CNK_OngAs soc._LA_Renter_Vulnerability_4-30-20.pdf

5. Sandler L. America could soon face a wave of single moms being evicted. A simple solution exists that could help them. Time. May 28, 2021. Available from: https://time.com/60525 56/evictions-single-moms-covid-19/

6. Lefowitz D, Armin JS. Why employment during and after COVID-19 is a critical women's health issue. Women's Health Issues. 2021;31(3):190-4. https://doi.org/10.1016/j.whi.2020. 12.004 .

7. Tucker J, Ewing-Nelson C. As eviction deadline looms, Black, Non-Hispanic women are over two times more likely than White, Non-Hispanic men to be behind on rent or mortgage payments. Washington, DC: National Women's Law Center. 2020. https://nwlc.org/wp-content/uploads/2020/12/pulseFS12.pdf. Accessed 23 Nov 2021

8. Shaw S, Lloyd C, Alvira-Hammond M. As pandemic eviction moratorium ends, households with children face greater risk of homelessness. Bethesda, MD: Child Trends. 2021. Available from: https://www.childtrends.org/publications/as-pandemiceviction-moratorium-ends-households-with-children-face-great er-risk-of-homelessness. Accessed 23 Nov 2021.

9. Kirkpatrick SI, Tarasuk V. Housing circumstances are associated with household food access among low-income urban families. J Urban Heal. 2011;88(2):284-96.

10. Meltzer R, Schwartz A. Housing affordability and health: evidence from New York City. Hous Policy Debate. 2016;26(1):80104. https://doi.org/10.1080/10511482.2015.1020321.

11. Chen KL, Wisk LE, Nuckols TK, Elmore JG, Steers WN, Zimmerman FJ. Unmet medical needs among adults who move due to unaffordable housing: California Health Interview Survey, 2011-2017. J Gen Intern Med. 2020:1-8. https://doi.org/10. 1007/s11606-020-06347-3

12. Kushel MB, Gupta R, Gee L, Haas JS. Housing instability and food insecurity as barriers to health care among low-income
Americans. J Gen Intern Med. 2006;21(1):71-7. https://doi.org/ 10.1111/j.1525-1497.2005.00278.x.

13. Rosen J, Angst S, De Gregorio S, Painter G. How do renters cope with unaffordability? Household-level impacts of rental cost burdens in Los Angeles. Los Angeles, CA: USC Sol Price Center for Social Innovation; 2020. Available from: https://socia linnovation.usc.edu/wp-content/uploads/2020/12/Price-Center_ RentersUnaffordability_Brief_Final.pdf

14. Pollack CE, Griffin BA, Lynch J. Housing affordability and health among homeowners and renters. Am J Prev Med. 2010;39(6):51521. https://doi.org/10.1016/j.amepre.2010.08.002.

15. Downing J. The health effects of the foreclosure crisis and unaffordable housing: a systematic review and explanation of evidence. Soc Sci Med. 2016;162:88-96. https://doi.org/10.1016/j. socscimed.2016.06.014.

16. Bills KL, West SM, Hargrove J. Housing cost burden and maternal stress among very low income mothers. J Sociol Soc Welf. 2019;46(1).

17. Sandel M, Sheward R, De Cuba SE, et al. Unstable housing and caregiver and child health in renter families. Pediatrics. 2018;141(2). https://doi.org/10.1542/peds.2017-2199

18. Newman SJ, Holupka CS. Housing affordability and investments in children. J Hous Econ. 2014. https://doi.org/10.1016/j.jhe.2013. 11.006

19. Nobari TZ, Whaley SE. Severe housing-cost burden and lowincome young children's exposure to adverse experiences: a crosssectional survey of WIC participants in Los Angeles County. Matern Child Health J. 2021;25(2):321-9. https://doi.org/10.1007/ s10995-020-03032-z.

20. Ma CT, Gee L, Kushel MB. Associations between housing instability and food insecurity with health care access in low-income children. Ambul Pediatr. 2008;8(1):50-7. https://doi.org/10. 1016/j.ambp.2007.08.004.

21. Money L, Lin R-G. L.A. County on verge of becoming COVID-19 epicenter. Los Angeles Times. December 18, 2020.

22. Ansari T, Lovett I. COVID-19 rates in Los Angeles have gone from worst to among the best. The Wall Street Journal. April 22, 2021.

23. PHFE WIC, First5LA. Los Angeles County WIC data demographics: comparing Los Angeles County to the WIC population. 2021. Accessed July 8, 2021. Available from: https://lawicdata.org/dataresearch/topics/demographics/

24. Wallace PM, Pomery EA, Latimer AE, Martinez JL, Salovey P. A review of acculturation measures and their utility in studies promoting Latino health. Hisp J Behav Sci. 2010;32(1):37-54.

25. Suro R, Findling H. Tax equality for immigrants: the indispensable ingredient for remedying child poverty in the United States. J Migr Hum Secur. 2021. https://doi.org/10.1177/2331502421 1034836

26. Botts J. Lawmakers pass $\$ 600$ stimulus checks plus boost for undocumented workers. CalMatters. February 23, 2021.

27. LABarometer Team. The affordability \& prosperity report. Los Angeles, CA: USC Dornsife Center for Economic and Social Research; 2021. Available from: https://cesr.usc.edu/sites/defau 1t/files/Affordability_Wave1_Report.pdf

28. Bailey ZD, Krieger N, Agénor M, Graves J, Linos N, Bassett MT. Structural racism and health inequities in the USA: evidence and interventions. Lancet. 2017;389(10077):1453-63. https://doi.org/ 10.1016/S0140-6736(17)30569-X.

29. Threet D, Aurand A, Pish M, Allen K, Carroll S. Costs of COVID19 evictions. Innovation for Justice Program at the University of Arizona and the National Low Income Housing Coalition; 2020. Available from: https://nlihc.org/sites/default/files/costs-of-covid 19-evictions.pdf

30. Joint Center for Housing Studies of Harvard University. The state of the nation's housing 2018. Cambridge, MA: Harvard 
University; 2018. Available from: https://www.jchs.harvard.edu/ sites/default/files/reports/files/Harvard_JCHS_State_of_the_Natio ns_Housing_2018.pdf

31. Airgood-Obrycki W, Hermann A, Wedeen S. The rent eats first: rental housing unaffordability in the US. Cambridge, MA: Harvard University; 2021. Available from: https://www.jchs.harvard. edu/sites/default/files/research/files/harvard_jchs_rent_eats_first_ airgood-obrycki_hermann_wedeen_2021.pdf

32. Wainer A, Zabel J. Homeownership and wealth accumulation for low-income households. J Hous Econ. 2020;47: 101624. https:// doi.org/10.1016/j.jhe.2019.03.002.

33. Grinstein-Weiss M, Key C, Guo S, Yeo YH, Holub K. Homeownership and wealth among low- and moderate-income households. Hous Policy Debate. 2013;23(2):259-79. https://doi.org/10.1080/ 10511482.2013.771786.

34. The White House Briefing Room. Biden-Harris administration announces initiatives to promote housing stability by supporting vulnerable tenants and preventing foreclosures. The White House. June 24, 2021. Accessed June 30, 2021.

35. California plans rent forgiveness using federal stimulus surplus. The New York Times. New York: NY; June 21, 2021. Available from: https://www.nytimes.com/2021/06/21/us/california-rentforgiveness.html

36. Wolffe K. COVID rent relief: what renters and owners need to know as California's eviction moratorium ends. KQED. September 23, 2021. Available from: https://www.kqed.org/news/11889 738/covid-rent-relief-what-renters-and-landlords-need-to-knowas-californias-eviction-moratorium-ends
37. Wagner D. Why aren't Angelenos who need rent relief applying for it. LAist. October 25, 2021. Available from: https://laist.com/ news/housing-homelessness/housing-is-key-rent-relief-los-angel es-california-application-outreach-eviction

38. Baldassari E. Thousands of renters and landlords await state aid as eviction moratorium set to expire. KQED. June 10, 2021.

39. Tobias M. Are immigrants getting left out of California's rent relief? CalMatters. October 13, 2021. Available from: https://calmatters. org/housing/2021/10/california-rent-relief-immigrants-barriers/

40. Los Angeles County Consumer \& Business Affairs. About L.A. County's Temporary Eviction Moratorium. Published 2021. Accessed June 30, 2021.

41. Nobari TZ, Whaley SE, Blumenberg E, Prelip ML, Wang MC. Severe housing-cost burden and obesity among preschool-aged low-income children in Los Angeles County. Prev Med Reports. 2019;13. https://doi.org/10.1016/j.pmedr.2018.12.003

42. The U.S. Department of Housing and Urban Development's (HUD's) Office of Policy Development and Research. Rental burdens: rethinking affordability measures. Available from: https://www.huduser.gov/portal/pdredge/pdr_edge_featd_article_092214.html Accessed July 11, 2021.

Publisher's Note Springer Nature remains neutral with regard to jurisdictional claims in published maps and institutional affiliations. 